\title{
Predicting Futures Price And Contract Portfolios Using The ARIMA Model: A Case of Nigeria's Bonny Light and Forcados
}

\author{
Arnold Adimabua Ojugo ${ }^{a,}{ }^{*}$, Rume Elizabeth Yoro ${ }^{b}$ \\ ${ }^{a}$ Department of Computer Science, Federal University of Petroleum Resources, Effurun 32001, Delta State, Nigeria \\ ${ }^{b}$ Department of Computer Science, Delta State Polytechnic, Ogwashi-Uku 32001, Delta State, Nigeria
}

\begin{abstract}
Market prediction has been the goal of many study as investors sought traded assets since the inception of the capital market. With each asset exchanged for money, investors seek to stay ahead the market trend in the hope of amassing profits. Businesses' growth (rise/fall) is evident upon their response to market behaviour. Thus, accurate prediction of the market often offers as its reward, enlarged financial portfolio. Market participants thus, seek to manage the risks associated with asset prices and its volatility, which can be rippled with chaos and complex tasks arising from a demand-supply curve. We seek to model the Oil market and forecast its price direction supported with empirical evidence using ARIMA model to analyze inputs in search of an optimal solution. We adopt the OPEC model to: (a) predict spot/futures-prices, (b) investigate why previous prediction was poor and price plummeted, and (c) compares value(s) from Ojugo and Yoro (2020) and Ojugo and Allenotor (2017). Results shows demand-supply curve rise (and a price rise) even though the policies and trend in real life scenario is currently experiencing a price plummet.
\end{abstract}

Keywords: Contango; Bardwardation; Oil Price; ARIMA, Futures price and contract; Nigeria;

\section{Introduction}

A pertinent issue in this market is its price direction, fluctuation and volatility, which once averaged $\$ 19$-to- $\$ 22$ per barrel from 1947-1997; It exceeded this mark with conflicts in Middle East. And growth interest of stakeholders to stabilize the oil energy market, emanated from major price shocks culminated by these events: (a) the Yom Kippur War marked price benchmarking at \$3 between 1948-1972, (b) the 1973 Arab oil embargo quadrupled its price from $\$ 3 /$ barrel to $\$ 12 /$ barrel in 1974 , (c) Iran's revolution and the Iran/Iraq war, further doubled prices from \$14/barrel in 1978 to \$35/barrel in 1981, (d) world recession and growth in alternative sources of energy took a swing in its demand-supply with a plumet in prices in 1980s. Efforts to surge up the price by OPEC (Organization of Petroleum Exporting Countries) was unsuccessful as member nations routinely violated rules and ignored limits placed by OPEC with Kuwait largely responsible for disseminating oil at cheaper prices. But, prices skyrocketed with Iraqi-invasion of Kuwait in 1990-91, and consequently increased the supply from other nations, (e) the United State recession in 1992 took a nose-dive till 1994 as oil attained its lowest-inflation-adjusted prices, (f) the growth in both US and Asia resulted in great demand of Oil, with demand growth by $2.8 \%$ in 1995 and 2.2\% in 1996 to increase prices increased by \$6/barrel (Sharma, 1998; Ojugo and Allenotor, 2017; Ojugo and Otakore, 2020; Ojugo, 2016).

There has been several price fluctuations, caused by the demand-supply chain imbalances and shocks in the energy market. And thus, have led to ever-changing futures-price and chaotic volatilities that result from a series of dynamic events such as change in regime, politics, economic crises, formation or breakdown in trade agreements, war or conflict in regions, unexpected weather patterns etc. Futures prices imbed expectations of market participants about how demand will evolve and how quickly its supply can react to events, to restore a balance (Azoff, 1994). Financial derivatives are used to forecast futures prices and volatility that are experienced by stakeholders, which consequently led to the adoption of various methods in both long-term and short-term markets. Others have sought stochastic

\footnotetext{
* Corresponding author.

E-mail address: ojugo.arnold@ fupre.edu.ng (Arnold Adimabua Ojugo)
} 
models (neural network, genetic algorithm etc) are now gaining in financial markets - emanating from their capabilities to explore domain task, be robust, portable, forecast accuracy and flexibility (Behmiri and Manso, 2013; Bopp and Sitzer, 1987).

\subsection{The Nigerian Frontier}

Nigeria is arguably the most influential and most strategic country in Africa in light of her population, vast hydrocarbon resources and her government's commitment to anti-corruption and African Unity. Nigeria is heavily dependent on its oil sector which accounts for about 90 percent of export revenues and 41 percent of Gross Domestic Product (Abosdera and Baghestani, 2004). Despite its relative abundance of mineral resources, the expansion of Nigeria's oil sector has been stymied by its antiquated infrastructure and the frustrating slow movement of goods through Nigeria's major ports. Nigeria's rapid economic development was largely attributed to her government's policies cum investment opportunities in institutional growth, human and technological capacity building in her oil and gas sector. These were facilitated by a number of systematic and deliberate policies directed toward building of a network of institutions for the promotion of technological and manpower capacity. Institutional capacity building have remained part of the strategies adopted by her government to tackle the incessant questions of technological backwardness (Ojugo and Allenotor, 2017; Ojugo and Otakore, 2020).

The eve of the oil boom showed that the Nigerian agro-based economy was relatively diversified, self-sufficient in food production, with enough to feed her populace and extra, for export. Nigeria had a strong export sector and budding industrial base with functioning laws, institutions, social and economic infrastructure as well as limitless job opportunities. Above all, security of life and property was adequate and foreign investors had confidence in the economy. This was the situation on ground before Nigeria's first export of crude oil in February 1958. Since 1970s, the oil and gas industry has become the fundamental to the Nigerian economy, providing the bulk of revenue as well as the foreign exchange earnings for the country. The discovery of oil and gas opened up the industry, brought in foreign participations like Mobil, Agip and Texaco/Chevron respectively to join the exploration efforts both in the onshore and offshore areas of Nigeria. This development was enhanced by the extension of the concessionary rights which aimed to accelerate the pace of exploration and production of petroleum. The overall increased demand from the non-OECD nations, and consequent supplies from 'unstable' Middle East indicates that more price fluctuations and volatilities will be a welcomed normal (Allenotor and Ojugo, 2017; Bopp and Sitzer, 1987). Thus, prediction of oil price direction is useful for investors and market participants (Ojugo, 2016).

The steer in financial derivatives and models to forecast the price emanates from the high interest to meet the needs of large-energy end-users, as an avenue to seek effective methods and well-thought out plans that will serve as informed opportunities to lock in fixed or max price for their supplies of Oil over a period in time. Thus, stakeholders are provisioned with tailored swaps and options to meet users specific needs (Ojugo and Allenotor, 2017). Oil swaps were initially traded on short-term maturities. Soon after, a new interest in long-term swaps and options on oil emerged and simultaneously, forced banks to adopt bonds and option-warrants as long term instrument. These were aimed at ensuring the survival and full migration to long-term swaps and options via instruments based on the price of West Texas Intermediate due to liquidity of traded futures- and option-contracts (Gabillon, 1991). However traded, oil continues to raise pricing complications for stakeholders due to volatility, hedging etc. But, researchers must seek means to reduce futures-prices at all cost via the determination of its term structures of prive and volatility (Vanstone, 2005). Simple models were first advanced to achieve this feat by simply extrapolating oil prices and volatility curves indexes. However, more complex models sought to harmonize the term structures of prices and volatilities around sensible hypotheses on oil market. The resulting model can be used for longer maturities if validated by price movements/maturities (Verleger, 1993; Gabillon, 1991).

\subsection{The Energy Market Models: A Literature Review}

\subsubsection{The OPEC Model(s)}

Numerous studies have sought to predict both spot- and futures prices of oil via the OPEC data as a means to set price right. These, have led to the adoption of disparate models based on the structure of its market and inventory. Tang and Hammoudeh (2002) advised on the errors in adopting such a model to include: (1) the inaccurate forecasts of gross 
domestic product for developing countries, (2) incorrect prediction in the increase in supply of oil by non-OPEC countries, and (3) the omission of market participants' expectations of OPEC's interventions. The OPEC is strongly motivated by 2-feats: (a) support for lower limit of oil prices via adoption of target zones, and (b) to maintain upper price limit, as excessively high prices encourage huge investment by non-OPEC nations and reduces OPEC's market share. To advance these motivations, OPEC models seek to establish price based on production quota, inventory level and futures-price expectations as determined by current data. They suggested that while its target zone offers good forecasts as price tends to upper/lower bound without price jumps; such models also exhibits large errors even with price within the bounds and they perform poorly if such prices experience price jump(s).

Kaufmann et al (2004) investigated the impact of OPEC on price using Granger's causality between capacity utilization, quotas and cheating on quotas, and the days of forward consumption of OECD oil stocks, computed by dividing OECD oil stocks by oil demand. They used the Persian Gulf War, seasonal dummies and quarterly data 1986-2000 to perform co-integration tests between variables that confirm a relation between real oil prices and model variables. Dees et al (2007) investigated Kaufmann et al (2004). Though their model showed fairly strong forecast; it was sensitive to the period and price volatility was caused by shocks. Also, their model showed weak results as it omitted variables responsible for increase in prices. To curb errors in Dees et al (2007), we included the utilization rate, non-linear supply conditions, and expectations about demand-supply imbalances. Their out-of-sample results showed strong forecast ability that accounted for the rise in price. In comparing their results with a random walk and future-contract benchmark, they discovered that the structural econometric model yielded a more accurate forecast.

Chevillon and Christine (2009) assessed the impact of the physical market, investigating determinant factors of real Brent spot price using quarterly data from 1988-2005. They modeled price as a function of six variables: OECD demand, non-OECD demand, OPEC quotas, OECD stocks, non-OECD stocks, and OPEC implicit target for real price. They incorporated the Iraqi Wars, terrorist attack of September 11, and Afghan War as dummy variables. The ir analysis concluded that concerns of the external shocks to the physical market caused an increase in prices.

\subsubsection{The Non-OPEC Model(s)}

Yang et al (2002) GARCH model described the determinants of United State oil prices by focusing on OPEC production, real US GDP, the price and income elasticity of demand for oil in the U.S to describe volatility of oil prices using monthly data from between 1975-2000. The model performs co-integration test and used ECM model to investigate short- and long-run relationships between oil demand and its prices, real GDP, and natural gas and coal prices in order to determine the price and income elasticity of demand. They simulated potential oil prices under different scenes of OPEC production reduction and concludes that production reductions will result in increases in oil prices; But, the magnitude and duration of increase depends on size of the OPEC reduction and the increase of domestic production by USA or other non-OPEC producers. Mirmirani and Li (2003) investigated between VAR and artificial neural network to predict prices using monthly light sweet oil futures prices of NYMEX (lagged oil prices), oil supply, petrol consumption and money supply as explanatory variables between 1980 and 2002. Their results indicate that ANN outperforms the VAR model.

\subsection{Motivation / Statement of Problem}

1. With a compendium of analysts and availability of many short-term and long-term models, why were they not harnessed by OPEC to continue to allow the dominance of Oil market? How is it they were not able to foresee the plummet in futures-price caused by shocks and volatility?

2. What minor shocks (external and internal influences) spiked the plummet in the futures cum 'expected' spot price(s) of oil? We seek to investigate what happened, why it happened and how it happened?

3. The chaotic and volatile nature of the market makes accurate prediction imperative; But, observing spot-prices alone is insufficient as unknown input not present from outset can yield inconclusive results along with falsepositive and true-negative errors in the classification. Thus, what pre-processing of the available dataset, what sample-period updates and broadening of data coverage will make for accurate predictions?

Predicted result trends in Ojugo and Allenotor (2017) were acceptable for a time; But, observed faulty forecasts. New investigations seeks to compare previous predictions. To overcome these shortfalls inherent in the adoption of chaotic 
oil dataset, we employ the autoregressive integrated moving average (ARIMA) model as adapted to handle such chaotic, dynamic and complex classification via a filter-technique that seeks to de-noise the dataset via a trend normalization employed to enhance adequate classification. This when used, will account for the underlying statistical properties and feats in oil dataset. It is believed that models and their consequent reports if put to good use, will it yield the desired effect and impact to overcome the existing bottlenecks that has continued to short-sight modellers/researchers that they forget the real goal namely: (a) to fix existing models as studies have shown that many model are a result of faulty (and often hideous) designs, (b) fathom the design of newer innovative models (when and where necessary) as models (no matter how good) are limited in their perception, and (c) create designs and new models that yield useful insight into the realistic, working scenario task ahead. Section(s) 2 introduces various hypotheses and parameter(s). Section 3 accounts for effective implementation and adaptation of unforeseen 'missed' parameters by previous models.

\section{Materials And Methods}

\subsection{Spaulding's Framework and Hypothesis}

The futures price of an asset is the price an asset sells in the future, which eventually converges to tomorrow's or its expected spot prices (on deadline of a transaction / delivery dates) in (Gabillon, 1991; Ojugo and Allenotor, 2017) denoted as: $\mathrm{F}_{\mathrm{p}}=\mathrm{S}_{\mathrm{p}}+\left(\mathrm{C}_{\mathrm{c}}+\mathrm{C}_{\mathrm{y}}\right)$. $\mathrm{F}_{\mathrm{p}}$ is futures price at time $t$ for delivery at $\mathrm{T}, \mathrm{S}_{\mathrm{p}}$ is spot price at $t, \mathrm{C}_{\mathrm{c}}$ is carry cost and $\mathrm{C}_{\mathrm{y}}$ is convenience yield. The convenience yield by definition notes: all goods attract a yield measured in terms of itself - as it is a compensation to the holder of the commodity and must be deducted from the carrying cost). If $\mathrm{C}_{\mathrm{y}}$ is higher than storage cost, then net carry cost is negative (backwardation). Eq. 1 is the relations between the futures and spot price, which yields a consistent result with the arbitrage valuation. Spaulding uses 3-hypotheses to explain the concept of futures-prices and how the futures-prices of today converges to tomorrow expected spot-price:

\subsubsection{Expected Hypothesis}

Assumes that a futures-price will equal the expected spot-price on a delivery date. The futures price does not deviate from the 'expected' future spot-price, which in turn does not yield a profit to either the long-term or short-term position(s). It posits that this does not present the reality as it is - as the expected future spot price is uncertain. Thus, the policy must employ the use of a risk premium available, to propel buyers to trade a position in the futures-contract or expected futures-price (Laurenti and Fernandes, 2012; Gabillon, 1991; Ojugo and Otakore, 2017).

\subsubsection{Contango-Backwardation Hypotheses}

This is the progressive increase in the futures-price of an asset with longer maturities. Many assets traded with futures prices have carrying-costs that include storage, insurance, and financing (and must in some cases, employ compensation for the risk of holding the asset). If the short-term position does not hold the underlying, then a risk premium must be paid to compensate for the risk. Contango is a state in which the futures prices of a commodity is higher than spot price since hedgers (commodity producers and users) and arbitraguers (non-commercial investors) are willing to pay more now (for a period in the future) for a commodity than its actual expected price of same commodity at that time in future. This influences a buyer to desirously pay premium on a commodity rather than pay for storage plus carry cost of buying the commodity for a current date. Contango is normal for non-perishable goods and includes carry costs such as warehouse fees, interest foregone on monies, less income from leasing commodity, time-value off money etc. Thus, a market is in contango if the spot price is lower than future-price (Chan, 1992; French, 2005; Ojugo and Allenotor, 2017).

Conversely, backwardation is a state in which futures price is below the spot price for the commodity. Thus, the spot price exceeds futures price since it includes the supply price on the spot and the remuneration for the risk of price fluctuation during the next period of production. It is a convenient way of rewarding the futures buyer for the risk he takes off the producer of the commodity. Backwardation exists if the price of futures contracts is below expected delivery date spot price. The theory of backwardation focuses on the analysis of hedging positions and its consequent transfer of risk provided by the futures price. Since prices for contracts with nearer maturity dates are higher than those with later maturities. Contango exists when the price of futures contracts is higher than the expected spot price on delivery date, and the price of futures contracts with later delivery dates are higher than those with sooner delivery 
dates. Thus, contango hypothesis stipulates that product buyers are the natural hedgers - since they also want a guaranteed price, so they are willing to pay a higher price than the expected spot price to achieve that result. This results in higher future prices for longer-term contracts. Contango market encourages investors to buy a near contract and take delivery to sell in the later months, and for companies to increase stockpiles of the commodity (Silvapulle and Mossa, 1999; Cherry, 2007; International Energy Agency, 2009).

\subsubsection{Net-Hedging Hypothesis}

Hedging is a way forward for any producer such that if spot-price of oil is $\$ \mathrm{x} / \mathrm{barrel}$ at $t$ and producer expect price to fluctuate between $t$ and $\mathrm{T}$ (maturity time for hedge). If producer is more concerned about risk of prices falling below $\$ y / b a r r e l$ and he is prepared to accept a max price of \$z/barrel. Hedging lets participants buy at \$y/barrel put and sell at $\$ \mathrm{z} / \mathrm{barrel}$ call - limiting backwardation/contango price risks to the range between $\$ \mathrm{y} / \mathrm{barrel}$ and $\$ \mathrm{z} / \mathrm{barrel}$. If the prices falls below $\$ \mathrm{y} / \mathrm{barrel}$ at $t, \$ \mathrm{z}$ call option is worthless and the $\$ \mathrm{y}$ put option is exercised to grant the producer the right to sell its output at $\$ y / b a r r e l$ (no matter how low prices go). If prices rise over $\$ z / b a r r e l$, the $\$ y$ put option becomes worthless as $\$ \mathrm{z}$ call option is exercised and producer will sell at $\$ \mathrm{z} /$ barrel (no matter how high prices go). But, if prices are between $\$ y / b a r r e l$ and $\$ z / b a r r e l$, neither option is exercised so that the producer sells at prevailing market price called collar (Dontwi et al, 2010). The strike price of the option can be set at any level, but the put and call options must be equally far out-of-the money if the cost of the put and call is to be the same. If the costs of the options are the same, the strategy is called zero collar (Moshiri and Foroutan, 2005). For backwardation (contango) state(s) to prevail in any market, depends on the resultant effects of the short-term or long-term positions and projections. Thus, net-hedge hypothesis stipulates that an excess of shorts will cause a normal backwardation, whereas an excess of longs will result in contango. The Capital Asset pricing modifies this by yielding risk required to compensate in the long-term positions for risks incurred entering a futures contract. So if an asset poses a higher risk with its beta is greater than 1; Then, future price must be lower than the expected spot price to compensate for the long-term position of greater risk (Labonte, 2004; McNeils, 2005; Allenotor and Ojugo, 2017).

\subsection{The ARIMA Model / Framework}

Structural models exhibits three (3) errors namely: (a) it yields inaccurate forecast of GDP especially for developing countries, and (b) it yields incorrect values on increase in demand-supply of oil to non-OPEC countries, and (c) omit market participant's expectations of OPEC intervention. Adoption of the autoregressive integrated moving average (ARIMA) model is to help curb inherent errors and flaws in structural models (Ojugo and Otakore, 2020; Ojugo, 2016). The general architecture of the ARIMA (p, d, q) proposed by Box-Jenkins is as below. It is one of the most common methods for building univariate series forecast, which models price and volatilities movements as a collection of functional variables such as OPEC behaviour, inventory level etc and other variables such as economic activities, interest rates and other asset prices. The ARIMA (p,d q) is of the form (Ojugo and Otakore, 2020; Allenotor and Ojugo, 2017):

$$
x_{t}=\theta_{0}+\sum_{i=1}^{p} \varphi_{1} x_{t-1}+\sum_{j-1}^{q} \theta_{j} u_{t-j}+u_{t}
$$

Where $\mathrm{p}$ and $\mathrm{q}$ refers to the order of the autoregressive term $\mathrm{x}_{\mathrm{t}}$ and the moving averages term $\mathrm{u}_{\mathrm{t}}$ respectively; $\varphi$ and $\theta$ are their respective coefficients, $d$ corresponds to the term $y_{t}$. We start the model identification by plotting the ACF and PACF against the different lags to determine the appropriate order of $\mathrm{p}$ and $\mathrm{q}$ for our model, which aims to make the model stationery. Once model is found to be stationery, we adapt and train the model to explore various ways we can have a fitting model for the Nigeria oil data. ARIMA model supports seasonal subset data as thus (Ojugo and Allenotor, 2017):

\subsubsection{Identification of Box-Jenkins / Seasonality}

This helps us to determine if a series is stationary, investigating the significant seasonality needed to be modelled therein. Stationarity of a series ensures that the series exhibits similar statistical behavior in time, which is often characterized as a constant probability distribution in time. Thus, it is satisfactory to consider the first two moments of a time series and define stationarity (or weak stationarity) trend by checking if the series contains trend upward/downward trend(s) that must be removed from the series. 


\subsubsection{Estimation and Diagnostic Checking for Accuracy}

Here, when particular ARIMA (p, d, q) model is selected the next step is to estimate the unknown parameters ( $p, d$ and $\mathrm{q})$. If $\mathrm{d} \neq 0$, it is necessary to difference the series $d$ times so that to get stationarity. The new series $\mathrm{W}_{\mathrm{t}}=(1-\mathrm{B})$ $\mathrm{dX}_{\mathrm{t}}$ will then be used to obtain estimates for the autoregressive, moving average and the mean of the series parameters. Frequently, after differencing, it is reasonable to assume that the new series has mean zero, in which case the parameter $\mu$ is dropped. The estimation procedure for time series is not unique.

\subsubsection{Forecasting / Prediction}

Given the model which was chosen it can be used to forecast the futures-price.

\section{Data Analysis, Findings and Discussion(s)}

\subsection{Model Implementation}

\subsubsection{Visualizing / Stationarize The Time-Series}

With univariate data, visual plots shows the series to check for trend and seasonality. If there are any trend and seasonality, they are removed. A stationary time series is one whose properties do not depend on the time of observation. Thus, time series with trend or seasonality are not stationary as they are affected by trend and seasonality values at different times. The stationary series will have no predictable patterns in long-term and the time plots will show the series to be roughly horizontal with constant variance. Series data such as the crude oil price exhibits nonstationarity (Coppola, 2007; Rouah and Vainberg, 2007). For estimation of its model, it is imperative to de-trend the data as we seek feats of interest using statistical inferences. A stationary series is flat without a trend, a constant variance over time, a constant autocorrelation over time and no periodic fluctuations. Fig 1 shows a non-constant mean and variance. A technique for making series of non-constant mean and variance stationary is the differencing.

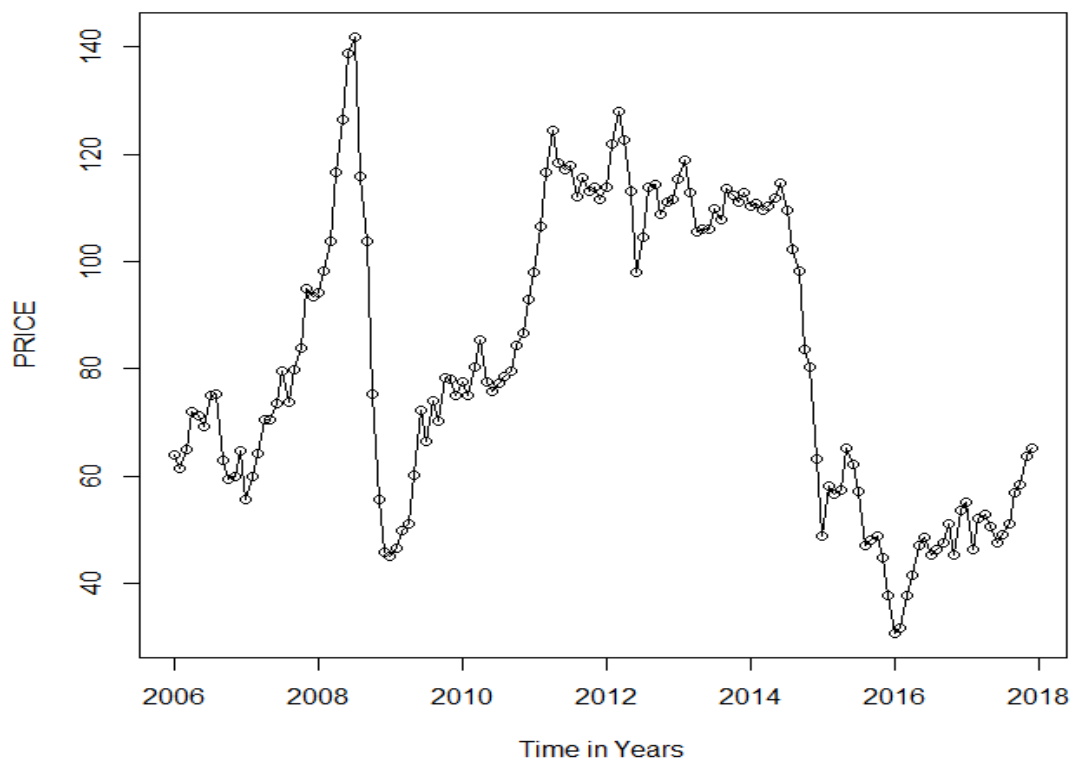

Fig. 1: Plot of Observed Price

\subsubsection{Finding $P$ and $Q$ Values $U$ sing $P A C F$ and $A C F$}

With series stationary, we select the appropriate ARIMA model by finding the most appropriate values for $\mathrm{p}$ and $\mathrm{q}$ in ARIMA (p,d,q). P and Q both refers to how many y-values and error-values are accounted for each time. We examine 
the correlogram (which shows the auto-correlation function as it correlates a variable at time $t$ and the same variable at time $t-k$ ), and partial correlogram (which removes the effect of shorter autocorrelation lags in computing the correlation at longer lags). The partial correlation at lag $k$ is autocorrelation between $Y_{t}$ and $Y_{t-k}$ not accounted for by the autocorrelation from the 1 st to the (k-1)st lags.

\subsubsection{Building The ARIMA Model}

We used the auto.arima() function to find the appropriate ARIMA model as well as the differencing of the data giving us a model of ARIMA $(2,0,1)$, which tells us that we need to take into account the Y-values at lag 2 from a given time point 0 tells us that the time series is stationary and we do not need any differencing again because it has been done once. Using the Y-value 1 - implies that the model takes into account the error term of 1 preceding /lagged values. We implement model via R-programming for these following reasons: (a) its high execution speed, (b) the availability of necessary libraries and tools for their open-source nature, (c) ease of implementation, and (d) flexibility of the system via $t$-series lib, forecast lib and ggplot2 lib.

\subsection{Data Analysis and Result Findings}

We use the augmented Dickey-Fuller (ADF) to check if series is stationary. ADF checks if a change in Y can be explained by both a lagged value and a linear trend. Result shows Dickey-Fuller $=-2.3416$, Lag order $=5$, p-value $=$ 0.434 . If the $p$-value is above 0.05 , then data is non-stationary. To make data stationary, we difference (by removing the previous Y-values) represented by the form in Eq. 2: $Y_{d t}=Y_{t}-Y_{t-1} \quad$ (2) as as in figure 2.

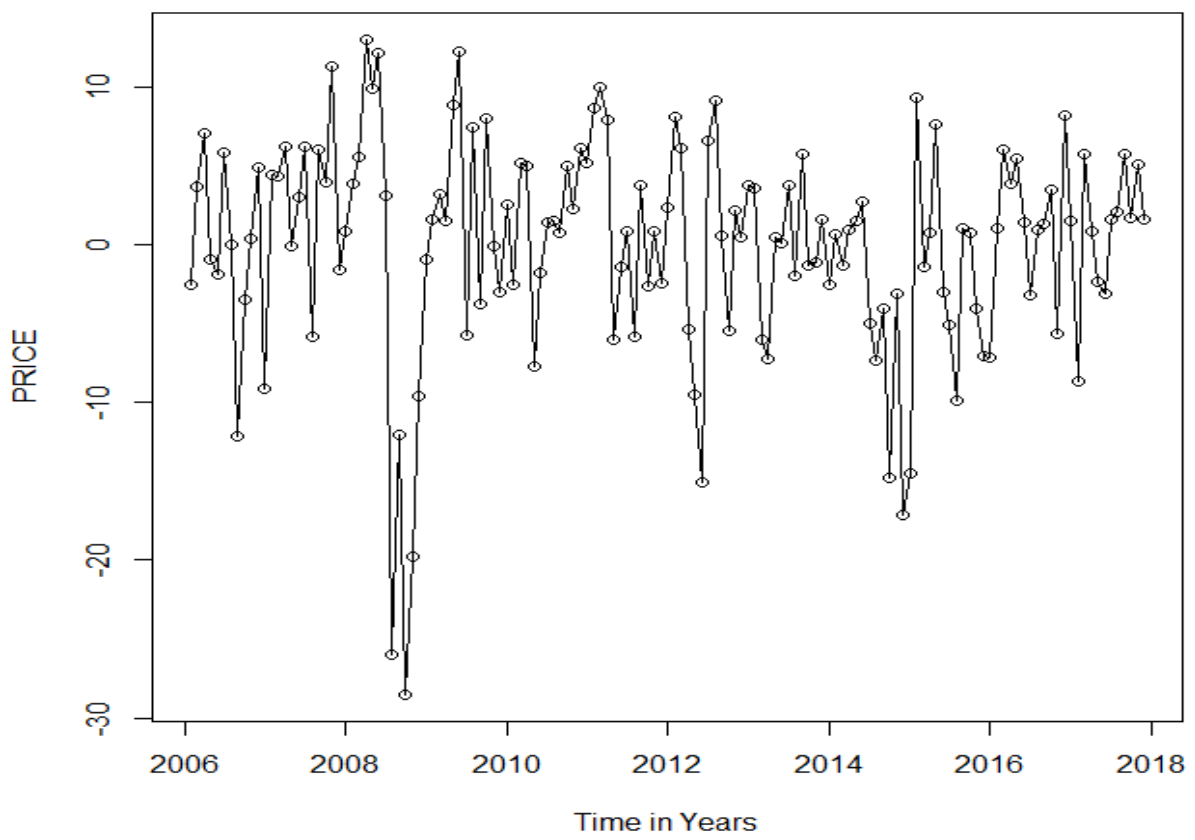

Fig. 2: Plot to Check for Stationarity

For the first difference for the ADF test result for the data are: Dickey-Fuller $=-6.1234$, Lag order $=5, p$-value $=0.01$. The p-value is less than 0.05 , we accept the null hypothesis and say the series is stationary. We take a second stationary test using the ADF with the result as data: Dickey-Fuller $=-2.272$, Lag order $=5$, p-value $=0.4632$. With the data as stationary, we employ ARIMA with p,d,q values in the form: $\operatorname{ARIMA}(1,1,0)$ - that is, AR of order 1 and a differnce(d) value of 1 and no moving average coefficient.

\subsection{Residual Data Analysis}

If the Box-Jenkins model selected is good enough for the dataset, we expect the residual white noise to be 
independent and a normal distribution. Fig. 3 shows the t-series residual plot.

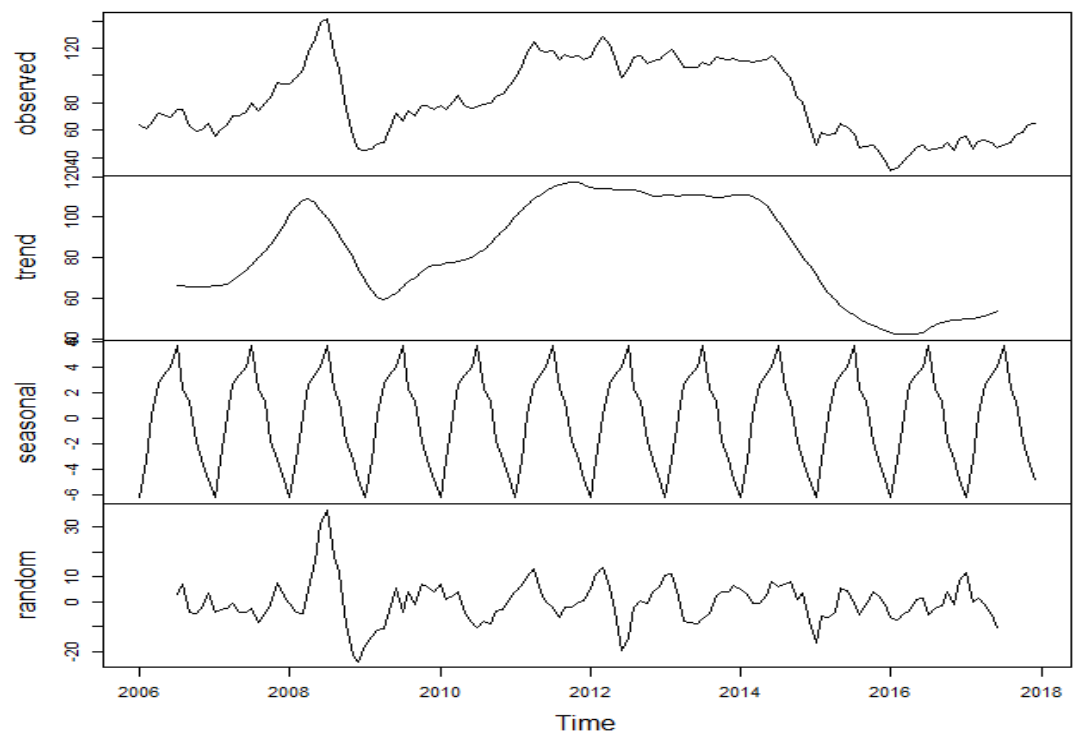

Fig. 3: Plot of the Decomposed Data

Figure 4-6 respectively shows the ACF residual plot, PACF residual correlo-gram and price plot. We then perform the Ljung-Box test based on the autocorrelation being different from zero - which seeks to either accept or reject the hypothesis that the residuals are independently distributed $\left(\mathrm{H}_{\mathrm{o}}\right)$.

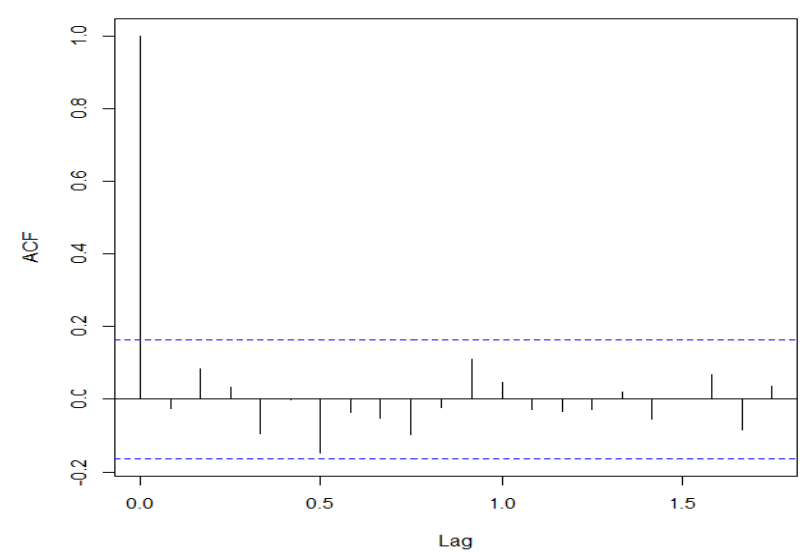

Fig. 4: Plot of the ACF of its Residual

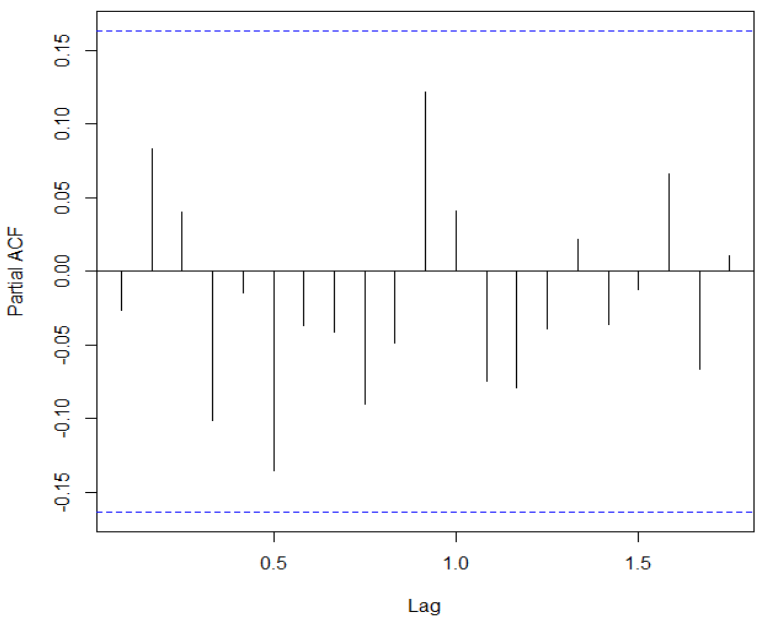

Fig. 5: Plot of the PACF of its Residual 


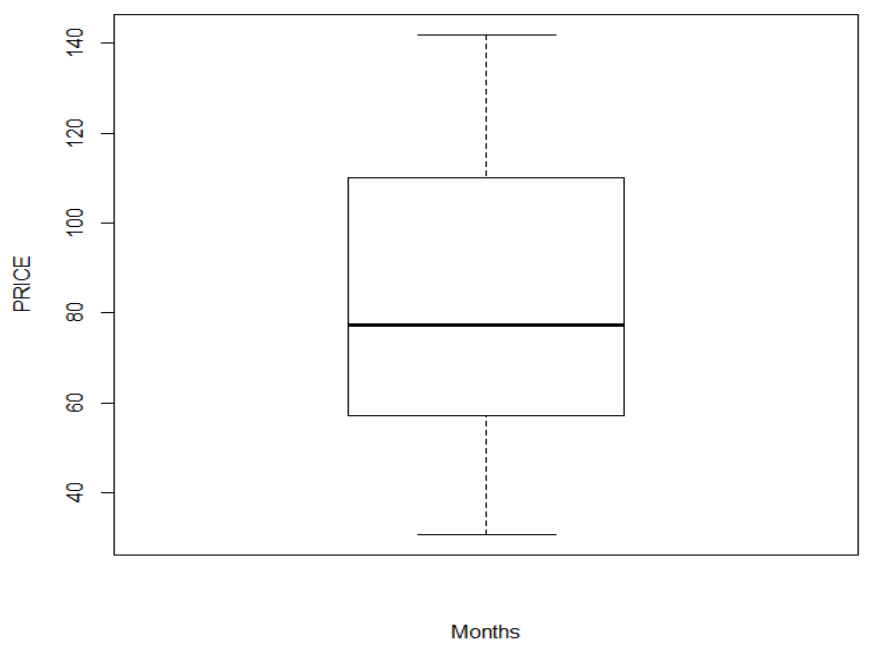

Fig. 6: Plot of the Stationary Data

From Section 1.3, item (2) is seen in Fig. 7, which shows futures-price direction monthly forecast for 2020 through to 2025. The spot-price is monthly average oil price (dollars/barrel) and its volatility is estimated from prices in previous year. For 2020, oil price volatility varies between 1.9012 and 0.312 . For 2021, the price volatility varies between 0.16 and 0.3542 ; while for 2021 - the price volatility varies from 0.412 to 2.092 for a 52-weeks futures maturity period. Results shows that the price of oil will rise due to demand from OPEC/non-OPEC countries; Rather, than a plummet in the near future. This results still holds for Ojugo and Yoro (2020) and Ojugo and Allenotor (2017) respectively.

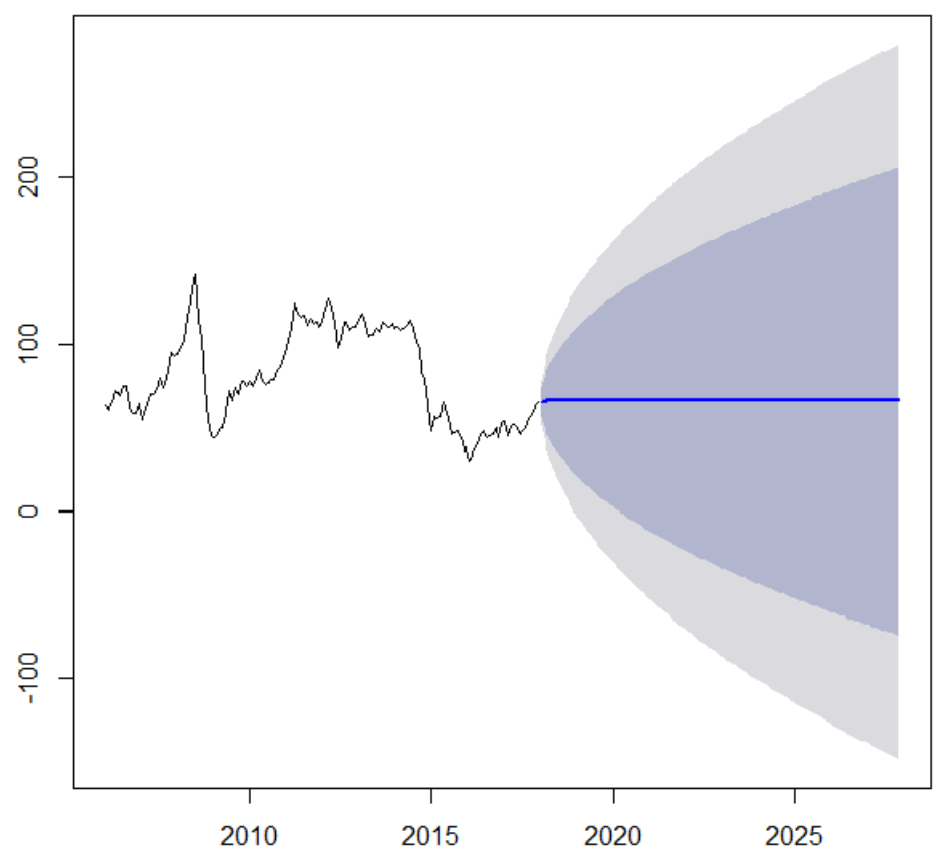

Fig. 7: Forecasted/Predicted Data Results

Item (1) is answered thus and we posit that the price plummet may have been contributed by two (2) facts: (a) a change in condition due to the training of the model using older dataset, and (b) energy is about politic/dominance, 
policies and vested interests. In time, it will results in shocks ranging from convenience yield, internal influences etc. Oil price direction emphasizes role of interest rates and convenience yield (adjusted spot-futures spread) to confirm that spot price normally exceed discounted futures-price. We explained why 'backwardation' is a welcomed normal; it can result to more hedging. Also, it is far better to hold a physical asset than hold futures-contracts as posited by hedging. The convenience yield behaves non-linearly; And, price response to it behaves same. Thus, futures-price are informative insights about future-spot prices only - except when spot prices substantially exceed futures-price (Dontwi et al, 2010; Oghenesode and Ojugo, 2018; Dees, 2015). Also, we note therein that unforeseen circumstances resulting from artificial scarcity, internal sabotage from some OPEC member states to circumvent limits band and to gain from back channels - a case in question is Kuwait (Ojugo, 2016; Oyemade and Ojugo, 2020; Ojugo and Oyemade, 2020; Ojugo and Eboka, 2018).

\section{Summary, Recommendation and Conclusions}

Oil price movement is very chaotic and poses complex nonlinear task, frequently influence not only by the economy rules but also by numerous complicated factors such as (Gabillon, 1991; Ojugo and Yoro, 2020; Ojugo and Otakore, 2020):

1. Demand-Supply effect influences greatly oil's price. Increased demand leads to price increase. Nigeria as an OPEC member with reserves, is keen on maintaining her demand-supply chain with an appropriate level of risks. This is the fundamental reasons in the chaotic price volatility. Continuous increase in demand yields economic growth with an increase in the amount of asset being exported - and vice versa.

2. Geopolitical Events: Much of Nigeria crude oil is located in region that are prone to political instability such as the Niger Delta region. Due to instability in the governmental and violence which bring instability in production and thereby making the place unsafe for investors and production. The government also determine how this price go due to various laws implement.

The ARIMA predicts well in all series but performs poorly in the presence of outliers, measurement errors and volatilities in the series. We used the Box Jenkins method to forecast model accuracy using SSE technique. Result showed that the ARIMA $(1,1,0)$ yields best forecast and it is quite simple to implement. It requires the entire training data to be loaded into memory before any computation. While, it is not suitable for multivariable datasets, we preprocessed the oil price dataset using Box-Jenkins with a framework that easily and strongly supports visualized prediction results - so that the end-user can fully understand and deal with the changes and dynamics within the data.

\section{References}

Abosedra, S and Baghestani, H., (2004). On predictive accuracy of futures prices, Energy Policy, pp. 1389-1393.

Allenotor, D., Ojugo, A.A., (2017). A financial option based price and risk management model for pricing electrical energy in Nigeria, Adv. in Multidisciplinary \& Sci. Res. J., 3(2): pp79-90

Azoff, M., (1994). Neural network time series forecasting of financial markets, John Wiley \& Sons, Chichester.

Behmiri, N.B and Manso, J.R.P., (2013). Crude oil forecasting techniques: a comprehensive review of literature, Alternative Investment Analyst Review in Social Science Review Network, doi: 10.2139/ssrn.2275428, 30-48

Bopp, E and Sitzer, S., (1987). Are petroleum futures prices good predictors of cash value?, Journal of Futures Market, 705-719, 1987.

Chan, K., (1992). A further analysis of the lead-lag relationship between the cash market and stock index futures market, The Review of Financial Studies, 7(6): 123-152.

Cherry, H. (2007). Financial Economics, 1st Ed. Actuarial Study Materials, NY: 3217 Wynsum Ave., Merrick.

Chevillon, G and Christine, R., (2009). Physical market determinants of the price of crude oil and the market premium, Energy Economics, 31(4), pp537-549

Coppola, A., (2007). Forecasting oil price movements: exploiting the information in futures market, 34, http://papers.ssrn.com/paper.taf?paper_id=967408 
Dees, S., (2015). Credit, asset prices and business cycles at the global level: A GVAR approach, The Energy Journal, 25(4), pp67-90, doi: 10.2307/41323358

Dees, S., Kaufmann, R.K., Karadeloglou, P., Sanchez, M., (2007). Modeling the world oil market: Assessment of a quarterly econometric model, Energy Policy, 35(1), pp178-191, doi: 10.1016/j.enpol.2005.10.017

Dontwi, I.K., Dedu, V.K and Davis, R., (2010). Application of options in hedging of crude oil price risk, American Journal of Social and Management Sciences, ISSN: 2156-1540, doi: 10.5251/ajsms.2010.1.1.67.74

French, M.W., (2005). Why and When do Spot Prices of Oil Revert to Futures Price Levels?, Finance and Economics Discussion Series Divisions of Res. \& Statistics and Monetary Affairs, Federal Reserve Board, Washington

Gabillon, J., (1991). Terms of oil future prices, Oxford institute of Energy Studies, ISBN: 0-948061-59-6

International Energy Agency (2009) Analysis of the impact of high oil prices on the global economy, Annual Report

Kaufmann, R.K., Dees, S., Karadeloglou, P., Sanchez, M., (2004). Does OPEC matter? An Econometric analysis of oil prices, The Energy Journal, 25(4), pp67-90, doi: 10.2307/41323358

Labonte, M., (2004). The effect of oil shocks on the economy: A review of the empirical evidence, RL31608.

Laurenti, M and Fernandes, J.M.M., (2012). Pricing crude oil calendar spread option, Master's Degree Thesis, Department of Finance, Copenhagen Business School

McNeils, D., (2005). Neural networks in finance gaining predictive edge in the market, Elsevier Academic Press.

Mirmirani, S., Li, C, H., (2003). A comparison of VAR and neural networks with genetic algorithm in forecasting price of oil, Advances in Econometrics, 19), pp62-67

Moshiri, S and Foroutan, F., (2005). Forecasting nonlinear oil futures prices, The Energy Journal, 27: 81-95

Oghenesode, L and Ojugo, A.A., (2018). Predicting Nigeria crude oil price using ARIMA model, Unpublished Bachelor's Thesis, Department of Maths. and Computer Science, Federal University of Petroleum Resources Effurun

Ojugo, A.A, (2016). Spread options pricing and hedging for Oil market: a case of Nigeria Bonny Light, Lecture Series of the Federal University of Petroleum Resources Effurun, Nigeria.

Ojugo, A.A., Allenotor, D., (2017). Forecasting price direction and spread options in oil volatility, Comp., Info., Sys. Dev. Info. \& Allied Res. Journal, 8(2): pp93-102, 2017, [web] www.isteams.net/copy-of-2016-archive-cisdijournal

Ojugo, A.A., A.O. Eboka., (2018). Modeling the computational solution of market basket associative rule mining approaches using deep neural network, Digital Technologies, 3(1): pp1-8, 2018, doi: 10.12691/dt-3-1-1

Ojugo, A.A., Otakore, O.D., (2020). Investigating the unexpected price plummet and volatility rise in energy market: comparative study of machine learning approaches, Quantitative Economics \& Management Studies, 1(3), doi: $10.35877 / 454 R I . q e m s 12119$

Ojugo, A.A and Ofualagba, G.O., (2016). Repositioning FUPRE Petroleum Varsity to tackle challenges in the oil and gas sector of Nigeria, Guardian Newspaper

Ojugo, A.A., Oyemade, D.A. (2020). Predicting diffusion dynamics of coronavirus in Nigeria through ties-strength threshold on a cascading SI-graph, Technology Report of Kansai University, TRKU-13-08-2020-10998, 62(8): pp4313-4323, 2020

Oyemade, D.A. Ojugo, A.A., (2020). A property oriented pandemic surviving trading model, International Journal of Advanced Trends in Computer Science and Engineering, 9(5): pp7397-7404

Rouah, F.D and Vainberg, G., (2007). Option pricing and volatility using Excel VBA, John Wiley and Sons, NY

Sharma, N., (1998). Forecasting oil price volatility, Masters of Art Thesis in Economics, Virginia Polytechnic Institute and State University

Silvapulle, P and Mossa, A., (1999). The relation between spot and future prices: Evidence from the crude oil market, The Journal of Futures Markets, 19(2), 175-193.

Tang, L and Hammoudeh, S., (2002). An empirical exploration of the world oil price under the target zone model, 


\section{Energy Economics, 24(6), pp577-596}

Vanstone, B., (2005). Trading in Australian stock market using artificial neural networks, McGraw Hill publication Verleger, P.K. (1993). Adjusting to Volatile Energy Prices, Institute for International Economics, Washington DC.

Yang et al, (2002). Market determinants of the price of crude oil and the market volatilities, Energy Economics, 31(4), pp537-549 